\title{
Obesity: outcome of standardized life-style change in a rehabilitation clinic. An observational study
}

This article was published in the following Dove Press journal:

Diabetes, Metabolic Syndrome and Obesity: Targets and Therapy

\author{
Helmuth Haslacher' \\ Hannelore Fallmann ${ }^{2}$ \\ Claudia Waldhäusl ${ }^{3}$ \\ Edith Hartmann ${ }^{2}$ \\ Oswald F Wagner' \\ Werner K Waldhäus| $\left.\right|^{2,4}$ \\ 'Department of Laboratory Medicine, \\ Medical University of Vienna, Vienna, \\ Austria; ${ }^{2}$ Rehabilitation Clinic for \\ Diabetes and Metabolic Diseases, \\ Moorbad Neydhartig, Neydharting, \\ Upper Austria, Austria; ${ }^{3}$ Department of \\ Radiotherapy, Medical University of \\ Vienna, Vienna, Austria; ${ }^{4}$ Department of \\ Medicine III, Medical University of Vienna, \\ Vienna, Austria
}

Correspondence: Werner K Waldhäusl Department of Medicine III, Medical University of Vienna, Waehringer Guertel 18-20, 1090 Vienna, Austria

Tel +436767535878

Fax +4313687101

Email werner.waldhaeusl@meduniwien. ac.at

\begin{abstract}
Purpose: To explore differences in baseline characteristics following three weeks of semistandardized in-patient care between patients with obesity without and with type 2 diabetes (T2D). Patients and methods: Patients without or with T2D were matched according to age, sex, and BMI. Food intake was restricted to $1,200-1,600 \mathrm{kcal} / \mathrm{d}$ to which a $400-600 \mathrm{kcal} / \mathrm{d}$ exercise load was added, and data were compared using Student's $t$-test, general linear models, and Spearman-rank correlations.

Results: At baseline, patients with obesity and T2D displayed, besides elevated blood glucose and $\mathrm{HbA}_{1 \mathrm{c}}$ values, higher serum liver enzymes $(p<0.001-0.05)$, triglycerides, and CRP $(p<0.01)$ and a greater prevalence of treated hyperlipidemia $(p<0.001)$ than those with plain obesity who showed only higher LDL and HDL cholesterol levels $(+9.0 \%$ and $+16.0 \%)$. In response to three-weeks of standardized life-style change, both groups improved their vital variables and risk scores $(p<0.001)$. While improvement in cholesterol slightly favored patients with plain obesity, the need for anti-hyperlipidemics $(+25 \%)$ rose in both groups, albeit that for anti-hypertensives $(+50 \%)$ increased only in patients with obesity and add-on T2D.

Conclusion: Moderate changes in lifestyle improve the clinical condition, including coronary heart disease and premature mortality risk scores (HARD-CHD and ABSI) in patients with obesity both in the absence and presence of T2D, with the latter seemingly increasing the risk of hepatic steatosis and systemic inflammation.
\end{abstract}

Keywords: obesity, standardized life-style change, liver disease, inflammation, rehabilitation clinic

\section{Introduction}

Obesity is a major health burden that shows no signs of abating. Its prevalence increases relentlessly, and at present affects 650 million people aged 18 years or older worldwide ( $13 \%$ of the adult population), ${ }^{1}$ both in affluent and poor populations. Such abnormal weight gain requires close medical attention as it clusters with numerous co-morbidities, including cardiovascular disease, stroke, hypertension, chronic kidney disease, dyslipidemia, inflammation, hypercoagulability, gout, type 2 diabetes (T2D), certain types of cancer, and sleep apnea. ${ }^{2,3}$ Causes of obesity include environmental and behavioral factors mediating positive calorie imbalance, diabesity (referring to obesity-associated diabetes and other conditions), and insulin insensitivity, ${ }^{4}$ the latter being in part due to fat overload. ${ }^{5}$ Treatment of obesity and its sequelae aims primarily at re-adaptation of the energy balance by behavioral and environmental changes, by altering food quality and intake ${ }^{6}$ as well as by physical exercise. Further attempts include medicalization and bariatric surgery, ${ }^{7}$ all of which have their limitations. ${ }^{6,8}$ 
Meanwhile, it is well established that one group of individuals with obesity is capable of maintaining a metabolically normal state, whereas a second group seems to be more inclined to experience the adverse metabolic effects of weight gain, ${ }^{9}$ including insulin resistance and subsequent $\mathrm{T} 2 \mathrm{D}$, a proclivity possibly driven by chronic inflammation due to reduced anti-inflammatory capacity. ${ }^{10}$ However, the issue as to whether both groups might differ in their response to lifestyle-based intervention still needs to be elucidated.

Therefore, this observational pre/post study compared the clinical outcome and associated costs in obese adults without or with T2D that were matched for age, sex, and body mass index (BMI). Comparisons were made regarding the improvements in vital, hepatic, and metabolic variables as well as the risk for coronary heart disease measured by the Framingham HARD CHD RISK SCORE (Framingham score), ${ }^{11}$ but also as to the need for medication against co-morbidities. To this end, both vital and metabolic variables were evaluated before and after a three-weeks stay in a Rehabilitation Clinic (RC) offering standardized lifestyle and structured medical education with adjustment of medication tailored to patient needs.

\section{Material and methods}

\section{Patients and study design}

This single center explorative study analyzed clinical outcome in adult patients with obesity (BMI $\geq 30 \mathrm{~kg} / \mathrm{m}^{2}$; age $>18$ years) with or without $\mathrm{T} 2 \mathrm{D}$ in response to a threeweek stay in RC. To this end, all patients with BMI $\geq 30 \mathrm{~kg} / \mathrm{m}^{2}$ admitted consecutively between June 2013 and June 2016 upon request of their respective physicians or general practitioners for treatment to our RC via the Austrian insurance system were primarily categorized as either obese without T2D (plain obesity, $\mathrm{N}=344,31.7 \%$ ) or obese with T2D ( $\mathrm{N}=741,68.3 \%)$, and then matched by an automatic algorithm (SPSS, IBM, Armonk, USA) for sex, age ( \pm 5 years), and BMI $\left( \pm 1 \mathrm{~kg} / \mathrm{m}^{2}\right)$. After matching and excluding two patients with secondary diabetes due to pancreatic insufficiency, 560 patients with obesity either without T2D $(\mathrm{N}=279)$ or with it $(\mathrm{N}=281)$ were eligible for analysis of their vital variables (blood pressure (BP), BMI, waist circumference, and ABSI - referring to a body shape index for premature mortality) - and metabolic variables (fasting blood glucose, $\mathrm{HbA}_{1 \mathrm{c}}$, lipids, liver enzymes, creatinine, and C-reactive protein CRP, the latter being a surrogate marker for inflammation) both at admission and discharge. In addition, changes were determined in medication requirement and Framingham scores in response to the three weeks of standardized life-style change in RC. The study was conducted in accordance with the Declaration of Helsinki and approved by the Ethics Committee of the Medical University of Vienna, and all patients gave written informed consent before their participation, with none dropping out.

\section{Examinations and measurements}

Medical history documents self-reported previous diagnoses, medications, and co-morbidities. In addition, smoking habits and compliance with recommendations for influenza and pneumococcal immunization ${ }^{12}$ were monitored as an indirect measure of the patients' compliance with health and treatment recommendations at home. Body weight $(\mathrm{kg})$ and height $(\mathrm{m})$ were documented without shoes and in light clothing with the BMI calculated as body weight divided by the square of height. BP was taken after a 5 mins rest using a sphygmomanometer in the sitting position by a trained nurse, and waist circumference was determined at the approximate midpoint between the last rib and iliac crest. ${ }^{13}$ The premature five year mortality risk was estimated by A Body Shape Index (ABSI) and calculated as the waist circumference in meters divided by the sum of $\mathrm{BMI}^{2 / 3}$ and body height ${ }^{1 / 2}(\mathrm{~m})$, and compared to the 0.0808 $\pm 0.0053 \mathrm{~m}^{11 / 6} \mathrm{~kg}^{-2 / 3}$ reported by others for the civilian noninstitutionalized US population. ${ }^{14,15}$ As suggested, a z-score was derived for comparison of baseline data between the two groups of obese patients without or with T2D. ${ }^{15}$ The Framingham score, ${ }^{11}$ a measure of the risk for developing a myocardial infarction or a stroke within the next ten years and given in $\%$, is reported as relative and absolute changes $v s$ baseline at discharge. By applying this score, the Framingham Heart Study reported for a population being initially free of coronary heart disease, intermittent claudication or diabetes and 30-79 years of age, an average ten year's risk of $6.0 \%$ in men and $1.2 \%$ in women. $^{16}$

Blood samples were drawn at admission and two days before discharge and analyzed at the MVZ für Laboratoriumsmedizin, Germany, applying ISO 15189 accredited procedures. This also included measurements of $\mathrm{HbA}_{1 \mathrm{c}}$, since its changes in response to prevailing glycemia are a continuous process and can already be seen as early as two weeks after intervention. ${ }^{17}$

\section{Diagnoses}

Obesity was defined as BMI $>30 \mathrm{~kg} / \mathrm{m}^{2}, \mathrm{~T} 2 \mathrm{D}$ according to American Diabetes Association criteria, ${ }^{18}$ hyperlipidemia 
as serum cholesterol $>200 \mathrm{mg} / \mathrm{dL}(5.17 \mathrm{mmol} / \mathrm{mol})$, and hypertension as arterial $\mathrm{BP}>140 / 90 \mathrm{mmHg}$ or mean arterial BP (MAP, diastolic BP plus BP-amplitude/3) >107 $\mathrm{mmHg}$ or as self-reported hypertension with current antihypertensive medication.

\section{Lifestyle}

At RC, patients were exposed to a standardized yet unmonitored life-style offering three meals/day rich in fruits and vegetables totaling $1,200-1,600 \mathrm{kcal} / \mathrm{d}$, low in salt (5 $\mathrm{mmol} / \mathrm{d}$ ), and bouts of exercise, such as hiking, swimming, or gymnastics, equivalent to an additional energy expenditure of $400-600 \mathrm{kcal} / \mathrm{d}$. The clinical intervention included educational seminars on metabolic diseases (WW, HF) and individual counseling by physicians (WW, HF, EH) with titration of medication to target (BP $140 / 90 \mathrm{mmHg}$; blood glucose fasting $<120,2$ hrs postprandially $<160 \mathrm{mg} / \mathrm{dl}$, cholesterol $<200 \mathrm{mg} / \mathrm{dl}$, LDL $<70 \mathrm{mg} / \mathrm{dl}$ ), by dietician educators, and peer pressure.

\section{Medication}

Medication was documented at admission and discharge as the number of tablets ingested per day for glucose-lowering drugs other than insulin (GLDs), insulin (units/d), lipid-lowering drugs (statins), antihypertensives (ACE inhibitors, angiotensin-II-receptorblockers ARBs, diuretics, calcium antagonists, betablockers, and alpha-blockers), anti-depressants, and for any other medication.

\section{Statistical analyses}

Unless otherwise indicated, continuous data are given as means \pm standard deviations. Categorical data are listed as counts and percentages. Continuous data were compared by Student's $t$-test and correlations were calculated, as applicable, according to Spearman ( $\rho$ ) or Pearson (r). Categorical data were compared by Pearson's $\chi^{2}$ tests. Improvements in vital/metabolic outcome after three weeks of rehabilitation were expressed as a relative reduction of the respective values vs those at admission, and calculated by general linear models with repeated measurements design. Statistical $p$-values were recalculated according to Benjamini/Hochberg and considered significant if $<0.05$. All calculations were done using SPSS 23 (IBM), Prism 6 (GraphPad Software, La Jolla, USA), and MedCalc 18 (MedCalc Software bvba, Ostend, Belgium).

\section{Results}

\section{Participants and baseline characteristics}

Baseline characteristics of patients with obesity without T2D $(\mathrm{N}=279)$ or with it $(\mathrm{N}=281)$ that were matched for age, sex, and BMI showed identical BP and LDL/HDL ratios, although serum levels of total HDL and LDL cholesterol were, respectively, $9 \%$ and $16 \%$ higher in patients with plain obesity $(p<0.001)$. In contrast and besides - by definition - higher blood glucose and $\mathrm{HbA}_{1 \mathrm{c}}$ values, somewhat higher peripheral concentrations of liver enzymes, triglycerides, and CRP $(p<0.001-p<0.05)$ were seen at admission in obese patients with T2D, who also had higher ABSI values $(p<0.001)$ than those without T2D (Table 1).

In addition, both groups reported at admission identical rates of vaccination against influenza (6-9\%) and pneumococci $(3-5 \%)$ as well as of nicotine consumption, albeit a higher prevalence of treated hyperlipidemia $(+18 \%$, $p<0.001)$ was seen in obese patients with $\mathrm{T} 2 \mathrm{D}$, who also displayed an $11 \%$ higher frequency of co-morbidities other than arterial hypertension, hyperlipidemia, cardiovascular disease, chronic kidney disease, and depression. In contrast, no difference between groups was seen in the frequency of hypertension, cardiovascular disease, chronic kidney disease, and depression.

Although CRP values increased continuously with rising BMI (plain obesity, $\mathrm{r}=0.27, p<0.001$, obesity with T2D: $\mathrm{r}=0.37, p<0.001)$, they leveled off at about $6 \mathrm{mg} / \mathrm{L}$ in excessively obese individuals (BMI $>50 \mathrm{~kg} / \mathrm{m}^{2}$ ) without T2D (Figure 1A).

\section{Outcome}

\section{Vital and metabolic variables}

Re-evaluating patients with obesity without or with type 2 diabetes at discharge after three weeks of lifestyle modification in $\mathrm{RC}$, both groups show almost identical changes in vital variables (body weight, BMI, waist circumference, BP) and metabolic variables with the exception of fasting blood glucose and $\mathrm{HbA}_{1 \mathrm{c}}$, which in patients with obesity plus type 2 diabetes were higher at baseline and more markedly reduced at discharge $(p<0.001)$ than in those without it (interactions: $p<0.001$ for different development; see also Tables 1 and 2). In parallel, remarkable improvements were seen in: (i) serum levels of $\gamma \mathrm{GT}$ (plain obesity: $-12 \pm 46 \mathrm{U} / 1$, obesity and T2D: $-17 \pm 46 \mathrm{U} / 1, p$ for main effect $<0.001$ ), (ii) LDL cholesterol (due to better statin compliance), (iii) LDL/HDL ratio $(-0,6)$, (iv) CRP (combined mean, $-0.8 \mathrm{mg} / \mathrm{dl}$ ), (v) Framingham score, 
Table I Baseline characteristics

\begin{tabular}{|c|c|c|c|}
\hline & Obesity without T2D & Obesity with T2D & $p$ \\
\hline $\mathrm{N}$ & 279 & 281 & \\
\hline Age [years]* & $51 \pm 9$ & $52 \pm 9$ & n.s. \\
\hline Sex* & $f=137(49 \%)$ & $f=138(39 \%)$ & n.s. \\
\hline Body weight $[\mathrm{kg}]$ & $1 / 4.3 \pm 18.8$ & $1 / 2.3 \pm 17.6$ & n.s. \\
\hline BMI $\left[\mathrm{kg} / \mathrm{m}^{2}\right]^{*}$ & $39.2 \pm 5.1$ & $39.0 \pm 5.2$ & n.s. \\
\hline Waist circumference $[\mathrm{cm}]$ & $123 \pm 12$ & $124 \pm 12$ & n.s. \\
\hline Framingham HARD CHD [\%] & $8.4 \pm 11.0$ & $8.5 \pm 9.9$ & n.s. \\
\hline ABSI $\left[\mathrm{m}^{11 / 6} \cdot \mathrm{kg}^{-2 / 3}\right]$ & $0.0819 \pm 0.004$ & $0.0833 \pm 0.004$ & $<0.001$ \\
\hline ABSI z-score & $-0.16 \pm 1.02$ & $+0.16 \pm 0.95$ & $<0.001$ \\
\hline \multicolumn{4}{|l|}{ Arterial blood pressure $[\mathrm{mmHg}]$} \\
\hline Systolic & $142 \pm 17$ & $142 \pm 18$ & n.s. \\
\hline Diastolic & $90 \pm 11$ & $89 \pm 11$ & n.s. \\
\hline MAP & $107 \pm 12$ & $106 \pm 12$ & n.s. \\
\hline \multicolumn{4}{|l|}{ Metabolic variables } \\
\hline Total cholesterol $[\mathrm{mg} / \mathrm{dL}]$ & $206 \pm 42$ & $189 \pm 43$ & $<0.001$ \\
\hline $\mathrm{LDL}[\mathrm{mg} / \mathrm{dL}]$ & $139 \pm 69$ & $120 \pm 38$ & $<0.001$ \\
\hline $\mathrm{HDL}[\mathrm{mg} / \mathrm{dL}]$ & $49 \pm 13$ & $44 \pm 12$ & $<0.001$ \\
\hline Triglycerides $[\mathrm{mg} / \mathrm{dL}]$ & $165 \pm 98$ & $195 \pm 139$ & $<0.01$ \\
\hline LDL/HDL ratio & $3.1 \pm 1.9$ & $2.9 \pm 1.2$ & n.s. \\
\hline Fasting blood glucose $[\mathrm{mg} / \mathrm{dL}]$ & $100 \pm 13$ & $|5| \pm 5 \mid$ & $<0.001$ \\
\hline $\mathrm{HbA}_{\mathrm{lc}}[\%]$ & $5.5 \pm 0.4$ & $7.4 \pm 1.6$ & $<0.001$ \\
\hline ASAT $[\mathrm{U} / \mathrm{L}]$ & $28 \pm 10$ & $31 \pm 13$ & $<0.01$ \\
\hline ALAT [U/L] & $35 \pm 17$ & $42 \pm 23$ & $<0.001$ \\
\hline$\gamma \mathrm{GT}[\mathrm{U} / \mathrm{L}]$ & $43 \pm 40$ & $60 \pm 97$ & $<0.05$ \\
\hline Creatinine $[\mathrm{mg} / \mathrm{dL}]$ & $0.9 \pm 0.3$ & $0.8 \pm 0.2$ & $<0.001$ \\
\hline Urea $[\mathrm{mg} / \mathrm{dL}]$ & $33 \pm 14$ & $32 \pm 9$ & n.s. \\
\hline Uric acid $[\mathrm{mg} / \mathrm{dL}]$ & $6.6 \pm 1.4$ & $6.6 \pm 1.5$ & n.s. \\
\hline CRP $[\mathrm{mg} / \mathrm{L}]$ & $5.1 \pm 5.0$ & $6.6 \pm 6.3$ & $<0.01$ \\
\hline
\end{tabular}

Notes: Baseline characteristics of vital and metabolic variables of obese patients without $(\mathrm{N}=279)$ and with type 2 diabetes $(\mathrm{N}=28 \mathrm{I})$ matched for sex, age, and $\mathrm{BMI}$. *Matching variables.

Abbreviations: ABSI, A Body Shape Index of premature mortality; MAP, mean arterial pressure; CHD, cardio-/cerebrovascular disease; CKD, chronic kidney disease; CRP, C-reactive protein; n.s., not statistically significant.

which fell to $5.5 \pm 6.1 \%$ (plain obesity) and $6.0 \pm 6.1 \%$ (obesity with T2D; $p$ for main effect $<0.001, p$ for interaction $=$ n.s.) from identical baselines $(8.4 \%$ and $8.5 \%$, respectively), and (vi) marginally also in ABSI. Improvement of BMI and body weight in response to three weeks in RC was more marked in patients with plain obesity than in those suffering from obesity with T2D (both $p_{\text {int }}<0.05$ ). Likewise, uric acid increased by $3 \%$ in patients with obesity and T2D but fell by approximately the same share in those without T2D ( $p$ for interaction $<0.001$ ).

The parallelism of BMI and CRP confirmed the inflammatory capacity of obesity (Figure 1A), which seemed, however, to level off in extremely obese patients (BMI $>50)$. Also of note was the correlation seen at admission and discharge, between Framingham scores and liver enzymes (ALAT $\rho=0.183$, ASAT $\rho=0.156$, gGT $\rho=0.305$ ), creatinine $(\rho=0.297)$, urea $(\rho=0.214)$, and triglycerides $(\rho=0.352)$ within patient groups (Figure 1B) as well as the correlation observed between ABSI and Framingham scores $(\rho=0.260, p<0.001)$.

\section{Medications}

At admission, the proportion of patients on antidepressants and any other medication did not differ between groups, while the use of anti-lipidemics was considerably lower in patients with plain obesity $(15 \%)$ than in those with obesity and T2D $(39 \%, p<0.001)$, and rose at discharge by about $25 \%$ for both groups. Of note also was the greater need of patients with obesity and T2D for antihypertensives at both admission $(72 \%$ vs $53 \%, p<0.001)$ and discharge $(72 \%$ vs $57 \%, p<0.001)$. The need for medication with anti-diabetic drugs, being restricted by 
A

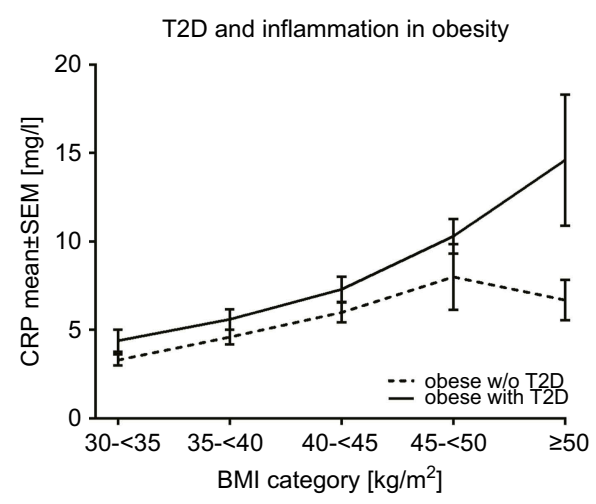

B

\begin{tabular}{|c|c|c|c|c|c|c|c|c|}
\hline ALAT & & $0.788^{\star \star \star}$ & $0.583^{* * *}$ & $0.166^{* * *}$ & $0.239^{\star \star *}$ & $0.146^{\star *}$ & 0.046 & -0.001 \\
\hline ASAT & $0.788^{\star \star \star}$ & & $0.446^{\star \star \star}$ & $0.148^{\star \star \star}$ & $0.119^{\star \star \star}$ & $0.144^{\star \star}$ & 0.050 & -0.015 \\
\hline gGT & $0.583^{* * *}$ & $0.446^{\star \star \star}$ & & $0.288^{* * *}$ & $0.340^{* * *}$ & $0.118^{\star *}$ & 0.045 & 0.060 \\
\hline HARD CHD & $0.166^{\star * *}$ & $0.148^{\star \star \star}$ & $0.288^{\star \star *}$ & & $0.351^{\star \star *}$ & $0.284^{\star * *}$ & $0.222^{\star \star \star}$ & -0.076 \\
\hline Trig. & $0.239^{\star * *}$ & $0.119^{\star * \star}$ & $0.340^{\star \star *}$ & $0.351^{* * *}$ & & 0.027 & 0.034 & 0.090 \\
\hline Crea & $0.146^{* *}$ & $0.144^{*}$ & $0.118^{*}$ & $0.284^{\star \star *}$ & 0.027 & & $0.432^{\star *}$ & $-0.168^{\star \star \star}$ \\
\hline Urea & 0.046 & 0.050 & 0.045 & $0.222^{* * *}$ & 0.034 & $0.432^{* *}$ & & $-0.138^{* *}$ \\
\hline \multirow[t]{2}{*}{ CRP } & -0.001 & -0.015 & 0.060 & -0.076 & 0.090 & $-0.168^{\star \star \star}$ & $-0.138^{* *}$ & \\
\hline & 安 & 㐫 & 攵 & $\begin{array}{l}\text { 오 } \\
\text { U } \\
\text { Q } \\
\frac{\alpha}{x} \\
\text { I }\end{array}$ & 㫣 & Ð & $\begin{array}{l}\text { ळ } \\
\stackrel{\varpi}{5}\end{array}$ & $\frac{\frac{n}{v}}{0}$ \\
\hline
\end{tabular}

Figure I Correlations. (A) Interdependence of inflammation (CRP) and BMI $\left(\mathrm{kg} / \mathrm{m}^{2}\right)$ in obese patients without and with type 2 diabetes (mean $\left.\pm \mathrm{SEM}\right)$, and (B) correlation matrix of Framingham HARD CHD Scores with biochemical values. Numbers represent correlation coefficients $($ Spearman's $\rho)$. $* * * p<0.001$; $* * p<0.01$, $* p<0.05$.

Abbreviations: T2D, type 2 diabetes mellitus; SEM, standard error or the mean; ALAT, alanine aminotransferase; ASAT, aspartate aminotransferase; gGT, gamma-glutamyl transferase; HARD CHD, Framingham HARD CHD Score; Trig., triglycerides; Crea, creatinine; CRP, c-reactive protein

Table 2 Outcome of obesity care

\begin{tabular}{|c|c|c|c|c|}
\hline & Obesity without T2D & Obesity with T2D & $P_{\mathrm{RC}}$ & PInt \\
\hline Vital variables & $N=279$ & $N=28 I$ & & \\
\hline BMI $\left[\mathrm{kg} / \mathrm{m}^{2}\right]$ & $-1.3 \pm 0.7$ & $-1.2 \pm 0.7$ & $<0.001$ & $<0.05$ \\
\hline Waist circumference $[\mathrm{cm}]$ & $-4 \pm 3$ & $-3 \pm 3$ & $<0.001$ & n.s. \\
\hline Body weight $[\mathrm{kg}](-\%$ of b.w.) & $-3.9 \pm 2.1(-3.4 \%)$ & $-3.5 \pm 2.1(-3.1 \%)$ & $<0.001$ & $<0.05$ \\
\hline Framingham HARD CHD & $-3.5 \pm 7.9$ & $-2.9 \pm 7.9$ & $<0.001$ & n.s. \\
\hline ABSI $\left[\mathrm{m}^{11 / 6} \cdot \mathrm{kg}^{-2 / 3}\right]$ & $-0.001 \pm 0.002$ & $-<0.001 \pm 0.002$ & $<0.001$ & n.s. \\
\hline \multicolumn{2}{|l|}{ Blood pressure $[\mathrm{mmHg}]$} & & & \\
\hline Systolic & $-15 \pm 19$ & $-16 \pm 19$ & $<0.001$ & n.s. \\
\hline Diastolic & $-9 \pm 13$ & $-9 \pm 13$ & $<0.001$ & n.s. \\
\hline MAP & $-11 \pm 13$ & $-12 \pm 13$ & $<0.001$ & n.s. \\
\hline \multicolumn{5}{|l|}{ Metabolic variables } \\
\hline Total cholesterol $[\mathrm{mg} / \mathrm{dL}]$ & $-38 \pm 32$ & $-32 \pm 32$ & $<0.001$ & n.s. \\
\hline LDL $[\mathrm{mg} / \mathrm{dL}]$ & $-35 \pm 52$ & $-27 \pm 52$ & $<0.001$ & n.s. \\
\hline $\mathrm{HDL}[\mathrm{mg} / \mathrm{dL}]$ & $-3 \pm 10$ & $-2 \pm 10$ & $<0.001$ & n.s. \\
\hline Triglycerides $[\mathrm{mg} / \mathrm{dL}]$ & $-42 \pm 104$ & $-47 \pm 104$ & $<0.001$ & n.s. \\
\hline LDL/HDL ratio & $-0.6 \pm 1.4$ & $-0.6 \pm 1.4$ & $<0.001$ & n.s. \\
\hline Fasting blood glucose $[\mathrm{mg} / \mathrm{dL}]$ & $-7 \pm 28$ & $-22 \pm 28$ & $<0.001$ & $<0.001$ \\
\hline $\mathrm{HbA}_{\mathrm{Ic}}[\%]$ & $-0.1 \pm 0.3$ & $-0.4 \pm 0.3$ & $<0.001$ & $<0.001$ \\
\hline ASAT [U/L] & $+<1 \pm 10$ & $+1 \pm 10$ & n.s. & n.s. \\
\hline ALAT $[\mathrm{U} / \mathrm{L}]$ & $+1 \pm 15$ & $+2 \pm 15$ & n.s. & n.s. \\
\hline$\gamma \mathrm{GT}[\mathrm{U} / \mathrm{L}]$ & $-12 \pm 46$ & $-17 \pm 46$ & $<0.001$ & n.s. \\
\hline Creatinine $[\mathrm{mg} / \mathrm{dL}]$ & $+<0 . I \pm 0 . I$ & $+<0.1 \pm 0.1$ & $<0.01$ & n.s. \\
\hline Urea $[\mathrm{mg} / \mathrm{dL}]$ & $-3 \pm 8$ & $-2 \pm 8$ & $<0.001$ & n.s. \\
\hline Uric acid $[\mathrm{mg} / \mathrm{dL}]$ & $-0.2 \pm 1.0$ & $+0.2 \pm 1.0 \uparrow$ & n.s. & $<0.001$ \\
\hline $\mathrm{CRP}[\mathrm{mg} / \mathrm{L}]$ & $-0.9 \pm 9.7$ & $-0.7 \pm 9.7$ & n.s. & n.s. \\
\hline
\end{tabular}

Notes: Changes vs baseline of vital and metabolic variables as well as of risk scores after three weeks at the RC in obese patients without (plain obesity) and with type 2 diabetes. Assessment by $2 \times 2$ MANOVAs with repeated measurement design and given as $\triangle$ Follow up - Baseline.

Abbreviations: $P_{R C}, p$-value for difference between baseline and follow up; $P_{I n t}$, $p$-value for interaction between temporal development and T2D. BMI, body mass index; ABSI, A Body Shape Index of premature mortality; CRP, C-reactive protein. 
Table 3 Medication

\begin{tabular}{|l|l|l|l|l|}
\hline \multirow{2}{*}{ Treatment } & \multicolumn{2}{l|}{ Obesity without T2D } & \multicolumn{2}{l|}{ Obesity with T2D } \\
\cline { 2 - 5 } & Admission & Discharge & Admission & Discharge \\
\hline Antilipidemics & $I ; I-I(I 5 \%)$ & $I ; I-I(20 \%)$ & $I ; I-I(39 \%)$ & $I ; I-I(48 \%)$ \\
Antihypertensives & $2 ; I-21 / 4(53 \%)$ & $I I / 2 ; I-2(57 \%)$ & $2 ; I-3(48 \%)$ & $2 ; I-3(72 \%)$ \\
Antidepressants & $I ; I-3(I 8 \%)$ & $I ; I-2(I 7 \%)$ & $2 ; I-3(22 \%)$ & $2 ; I-3(20 \%)$ \\
Any other medication & $2 ; I-3(60 \%)$ & $2 ; I-3(64 \%)$ & $2 ; I .3(65 \%)$ & $2 ; I-3(67 \%)$ \\
\hline $\begin{array}{l}\text { Antidiabetic drugs } \\
\text { GLDs } \\
\text { Insulin }\end{array}$ & $0(0 \%)$ & $0(0 \%)$ & $2 ; 2-3(73 \%)$ & $2 ; 2-3(73 \%)$ \\
\hline
\end{tabular}

Notes: Number of tablets (\%) ingested for a given co-morbidity by obese patients without or with type 2 diabetes at admission to and at discharge from the RC. Abbreviation: GLDs, glucose-lowering drugs.

definition to patients with obesity and T2D, did not change quantitatively but only qualitatively (details not shown) between admission and discharge (Table 3 ).

\section{Costs}

Costs of both medication (Table 4A) and stay in RC were modest ( $€ 131 / d$ ) compared to those incurred in a standard hospital (range $€$ 594-1,145; Table 4B).

\section{Discussion}

This pre/post observational study was conducted on 560 obese patients either without or with type 2 diabetes that were matched for age, sex, and BMI. We showed that three weeks of standardized life-style change at a metabolic RC not only reduced body weight to the same extent as seen in response to a low fat diet, ${ }^{6}$ but also improved cardiovascular risk by $30-35 \%$ - as assessed by Framingham HARD CHD score, and reduced the risk of premature mortality by $1 \%$ - as determined by ABSI, independently of T2D.

In response to three weeks in $\mathrm{RC}$, the improvement seen in CRP, lipid and glucose metabolism, and liver function paralleling weight loss seems to reflect a reduction of obesity-associated inflammatory capacity, ${ }^{19}$ hepatic steatosis, ${ }^{20}$ as well as of triglyceride and of glucose synthesis. ${ }^{21}$ This is consistent with previous observations reporting full reversibility of metabolic diseases in response to diet adjustments,

Table 4 Costs of medication (a) and hospitalization (v)

\begin{tabular}{|c|c|c|c|c|}
\hline & \multicolumn{2}{|c|}{ Obesity without T2D } & \multicolumn{2}{|c|}{ Obesity with T2D } \\
\hline & Admission & Discharge & Admission & Discharge \\
\hline \multicolumn{5}{|l|}{ (A) Medication (costs/day) } \\
\hline GLDs & $€ 0$ & $€ 0$ & $€ 70$ & $€ 43$ \\
\hline Insulin & $€ 0$ & $€ 0$ & $€ 346$ & $€ 286$ \\
\hline Antilipidaemics & $€ 63$ & $€ 67$ & $€ 105$ & $€ 99$ \\
\hline Antihypertensives & $€ 16$ & $€ 2 I$ & $€ 45$ & $€ 54$ \\
\hline Antidepressants & $€ 46$ & $€ 38$ & $€ 57$ & $€ 49$ \\
\hline Total medication:costs/day & $€ 125$ & $€ 126$ & $€ 623$ & $€ 531$ \\
\hline Average costs/person.year & $€ 163$ & $€ 165$ & $€ 809$ & $€ 690$ \\
\hline \multicolumn{5}{|c|}{ (B) Hospitalization (costs/day) } \\
\hline University hospital & \multicolumn{4}{|l|}{$€ 1,145$.- } \\
\hline Acute hospital & \multicolumn{4}{|c|}{$€$ 682.- $[594-816]$} \\
\hline Acute hospital ICU & \multicolumn{4}{|c|}{$€ I, 8 \mid 3 .-[I, 35 I-2,042]$} \\
\hline Rehabilitation clinic & \multicolumn{4}{|l|}{$€|3| .-$} \\
\hline
\end{tabular}

Notes: ${ }^{a}$ Changes of costs of medication in response to hospitalization at discharge vs at admission and ${ }^{b}$ costs of hospitalization per se [€/d and patient; range] depending on hospital type in Austria. Data: Parliamentary records 89I/AB XXV. GP, https://www.parlament.gv.at/PAKT/VHG/XXV/AB/AB_0089I/imfname_349I74.pdf, and https://www. akhwien.at/default.aspx?pid=789.

Abbreviations: GLDs, glucose-lowering drugs; €, Euro; ICU, intensive care unit. 
continuous exercise or bariatric surgery, particularly at an early stage. $^{20,22,23}$

Comparing the need for medication at admission and discharge, this report also unveils considerable neglect in the needs for treatment at home of hyperlipidemia and arterial hypertension in both groups.

The reduction in body weight shown in response to three weeks in RC by the two groups studied is identical to the $-3.5 \mathrm{~kg}$ observed in response to a low-fat diet at 24 weeks by others, ${ }^{6}$ and provides a solid basis for further weight reduction, which is a major goal in the prevention and treatment of T2D. Maintaining this goal corrects many of the metabolic abnormalities associated with obesity, including insulin resistance, T2D, hypertension, dyslipidemia, and obesity-associated functional impairments. ${ }^{24}$

Poor attention for personal health in patients with obesity without and with T2D is also indirectly reflected by their low compliance with requested vaccinations against pneumococci and influenza, ${ }^{12,25}$ as well as by the high prevalence of active smokers among these groups $(25 \%$ and $20 \%$ for obese patients with or without T2D, respectively), which is far above the $15 \%$ reported for the population of Sweden. ${ }^{26}$

In general, T2D carries a two- to fourfold risk for cardiovascular disease. ${ }^{27}$ Considering the higher rate of arterial hypertension and dyslipidemia observed in patients with obesity and T2D in the present study stresses T2D's aggravating and detrimental effect in obese patients who, even if metabolically still healthy, nevertheless carry a higher risk of cardiovascular disease than metabolically healthy individuals with normal weight. ${ }^{28}$

The observed improvement in the risk scores of our obese patients as well as in both their vital and metabolic variables in response to simple standardization of lifestyle at low cost in RC suggests this approach should also be considered in clinical practice as it could well be continued and established at home. Such exposure to modest calorie restriction and increased physical exercise has been shown in the past in a variety of diabetes-prevention studies to be superior to treatment with anti-diabetic drugs. ${ }^{29,30}$

The present study has several limitations. Firstly, the clinical setting of RC does not allow for untreated control groups, as patients are admitted for treatment of their clinical condition. Secondly, compliance with standardization of lifestyle in RC is the patients' choice. However, non-compliance is seemingly minimal as failure to reduce body weight is seen only in $1 \%$ of the enrolled patients. Thirdly, the outcome of a pre/post study cannot be extrapolated to the long term since the study can only document what is achieved during a set period of time. However, given the need for new approaches for helping people to deal with obesity and its sequelae, ${ }^{31}$ imprinting patients with a healthier mode of living in $\mathrm{RC}$ might be a welcome option to induce more healthy attitudes in daily life compared to, say, the introduction of synthetic fat products $^{32}$ or compulsory calorie labeling, ${ }^{33}$ which might easily go unnoticed.

The study's strengths include the homogeneity of its large groups of matched obese patients without or with T2D, thereby providing sufficient power to detect clinically relevant pre/post differences in outcome of vital and metabolic variables. Furthermore, the study's near real-life design holds promise to permit patients to adapt their lifestyle at home accordingly, provided there is sufficient individual motivation to cooperate so as to capitalize on associated health benefits. However, to prove this point, more elaborate studies with longer duration of life-style intervention will be required to demonstrate that the simple measures applied here could make a difference in longterm obesity care. Such studies should also look at the change in body weight and metabolic variables as legacy effect of previous life style modification.

\section{Conclusion}

A three-week regimen of standardized obesity care in a metabolic RC can trigger weight loss and improve vital and metabolic variables in obese patients, without or with type 2 diabetes almost to the same extent.

\section{Acknowledgments}

We thank the patients who chose to participate in this study, the physical therapy staff in RC for their hard work and dedication, and Aner Gurvitz for English language editing. The authors declare that they have no conflict of interest, and received no funding for the conduct of this study. Raw data can be requested from the corresponding author. This study received no additional funding.

\section{Disclosure}

The authors report no conflicts of interest in this work.

\section{References}

1. Whiting DR, Guariguata L, Weil C, Shaw J. IDF diabetes atlas: global estimates of the prevalence of diabetes for 2011 and 2030. Diabetes Res Clin Pract. 2011;94(3):311-321. doi:10.1016/j.diabres.2011.10.029 
2. World Health Organization. Obesity: Preventing and Managing the Global Epidemic. Geneva: World Health Organization; 2000.

3. Gregg EW, Shaw JE. Global health effects of overweight and obesity. N Engl J Med. 2017;377(1):80-81. doi:10.1056/NEJMe1706095

4. Zimmet P, Alberti KG, Shaw J. Global and societal implications of the diabetes epidemic. Nature. 2001;414(6865):782-787. doi:10.1038/414782a

5. Roden M, Price TB, Perseghin G, et al. Mechanism of free fatty acid-induced insulin resistance in humans. J Clin Invest. 1996;97 (12):2859-2865. doi:10.1172/JCI118742

6. Shai I, Schwarzfuchs D, Henkin Y, et al. Weight loss with a low-carbohydrate, Mediterranean, or low-fat diet. $N$ Engl $J$ Med. 2008;359(3):229-241. doi:10.1056/NEJMoa0708681

7. Heymsfield SB, Wadden TA. Mechanisms, pathophysiology, and management of obesity. $N$ Engl J Med. 2017;376(3):254-266. doi:10.1056/NEJMra1514009

8. Adams TD, Davidson LE, Litwin SE, et al. Weight and metabolic outcomes 12 years after gastric bypass. $N$ Engl J Med. 2017;377 (12):1143-1155. doi:10.1056/NEJMoa1700459

9. Fabbrini E, Yoshino J, Yoshino M, et al. Metabolically normal obese people are protected from adverse effects following weight gain. J Clin Invest. 2015;125(2):787-795. doi:10.1172/JCI78425

10. Jais A, Einwallner E, Sharif O, et al. Heme oxygenase-1 drives metaflammation and insulin resistance in mouse and man. Cell. 2014;158(1):25-40. doi:10.1016/j.cell.2014.04.043

11. Expert Panel on Detection Evaluation and Treatment of High Blood Cholesterol in Adults. Executive Summary of The Third Report of The National Cholesterol Education Program (NCEP) expert panel on detection, evaluation, and treatment of high blood cholesterol in adults (Adult Treatment Panel III). JAMA. 2001;285(19):2486-2497.

12. Smith SA, Poland GA. Influenza and pneumococcal immunization in diabetes. Diabetes Care. 2004;27 Suppl 1:S111-S113.

13. World Health Organization. WHO STEPS surveillance manual; 2017. Available from: https://www.who.int/ncds/surveillance/steps/STEPS_ Manual.pdf. Accessed August 22, 2018.

14. Lee DY, Lee MY, Sung KC. Prediction of mortality with A Body Shape Index in Young Asians: comparison with body mass index and waist circumference. Obesity. 2018;26(6):1096-1103. doi:10.1002/oby.22193

15. Krakauer NY, Krakauer JC. A new body shape index predicts mortality hazard independently of body mass index. PLoS One. 2012;7 (7):e39504. doi:10.1371/journal.pone.0039504

16. Framingham Heart Study. Hard coronary heart disease (10-year risk); 2018. Available form: https://www.framinghamheartstudy.org/fhsrisk-functions/hard-coronary-heart-disease-10-year-risk/. Accessed August 22, 2018.

17. Hirst JA, Stevens RJ, Farmer AJ. Changes in HbAlc level over a 12-week follow-up in patients with type 2 diabetes following a medication change. PLoS One. 2014;9(3):e92458. doi:10.1371/journal.pone. 0092458
18. Marathe PH, Gao HX, Close KL. American diabetes association standards of medical care in diabetes 2017. J Diabetes. 2017;9 (4):320-324. doi:10.1111/1753-0407.12524

19. Larsson A, Hansson LO, Akerfeldt T. Weight reduction is associated with decreased CRP levels. Clin Lab. 2013;59(9-10):1135-1138.

20. Petersen KF, Dufour S, Befroy D, Lehrke M, Hendler RE, Shulman GI. Reversal of nonalcoholic hepatic steatosis, hepatic insulin resistance, and hyperglycemia by moderate weight reduction in patients with type 2 diabetes. Diabetes. 2005;54(3):603-608.

21. Sato F, Tamura Y, Watada H, et al. Effects of diet-induced moderate weight reduction on intrahepatic and intramyocellular triglycerides and glucose metabolism in obese subjects. J Clin Endocrinol Metab. 2007;92(8):3326-3329. doi:10.1210/jc.2006-2384

22. Taylor R. Type 2 diabetes: etiology and reversibility. Diabetes Care. 2013;36(4):1047-1055. doi:10.2337/dc12-1805

23. Moller K, Ostermann AI, Rund K, et al. Influence of weight reduction on blood levels of C-reactive protein, tumor necrosis factor-alpha, interleukin-6, and oxylipins in obese subjects. Prostaglandins Leukot Essent Fatty Acids. 2016;106:39-49. doi:10.1016/j.plefa.2015.12.001

24. Pi-Sunyer FX. Short-term medical benefits and adverse effects of weight loss. Ann Intern Med. 1993;119(7 Pt 2):722-726.

25. Mancuso P. Obesity and respiratory infections: does excess adiposity weigh down host defense? Pulm Pharmacol Ther. 2013;26 (4):412-419. doi:10.1016/j.pupt.2012.04.006

26. Rutqvist LE. Population-based survey of cessation aids used by Swedish smokers. Harm Reduct J. 2012;9:38. doi:10.1186/14777517-9-38

27. Rawshani A, Rawshani A, Franzen S, et al. Mortality and cardiovascular disease in type 1 and type 2 diabetes. $N$ Engl J Med. 2017;376 (15):1407-1418. doi:10.1056/NEJMoa1608664

28. Caleyachetty R, Thomas GN, Toulis KA, et al. Metabolically healthy obese and incident cardiovascular disease events among 3.5 million men and women. J Am Coll Cardiol. 2017;70(12):1429-1437. doi:10.1016/j.jacc.2017.07.763

29. Chiasson JL, Josse RG, Gomis R, Hanefeld M, Karasik A, Laakso M. Acarbose for prevention of type 2 diabetes mellitus: the STOP-NIDDM randomised trial. Lancet. 2002;359(9323):2072-2077. doi:10.1016/ S0140-6736(02)08905-5

30. Knowler WC, Barrett-Connor E, Fowler SE, et al. Reduction in the incidence of type 2 diabetes with lifestyle intervention or metformin. $N$ Engl J Med. 2002;346(6):393-403. doi:10.1056/NEJMoa012512

31. Bleich SN. A road map for sustaining healthy eating behavior. $N$ Engl J Med. 2018;379(6):507-509. doi:10.1056/NEJMp1805494

32. Jackson MY, Proulx JM, Pelican S. Obesity prevention. Am J Clin Nutr. 1991;53(6 Suppl):1625s-1630s.

33. Block JP. The Calorie-Labeling Saga - federal preemption and delayed implementation of public health law. $N$ Engl $J$ Med. 2018;379(2):103-105. doi:10.1056/NEJMp1802953

Diabetes, Metabolic Syndrome and Obesity: Targets and Therapy

\section{Publish your work in this journal}

Diabetes, Metabolic Syndrome and Obesity: Targets and Therapy is an international, peer-reviewed open-access journal committed to the rapid publication of the latest laboratory and clinical findings in the fields of diabetes, metabolic syndrome and obesity research. Original research, review, case reports, hypothesis formation, expert opinion and commentaries are all considered for publication. The manuscript management system is completely online and includes a very quick and fair peer-review system, which is all easy to use. Visit http://www.dovepress.com/testimonials.php to read real quotes from published authors. 